\title{
Elastoplastic Damaging Model for Adhesive Anchor Systems. II: Numerical and Experimental Validation
}

\author{
Antonino Spada ${ }^{1}$; Piervincenzo Rizzo²; and Giuseppe Giambanco ${ }^{3}$
}

\begin{abstract}
This paper presents the numerical and experimental validation of the analytical elastoplastic damaging model proposed in the companion paper (Part I). The validation was carried out by describing the pullout failure of epoxy adhesive anchors. Pullout tests were simulated numerically and performed experimentally. Several specimens made of a rebar embedded in a hardened concrete cylinder by means of polyester resin were tested. Conventional strain gauges and acoustic emission (AE) sensors were used to evaluate the structural response of the system and to monitor the onset and progression of structural damage, respectively. The parametric analysis and the moment tensor analysis of the AE data were used to discriminate among different sources of damage. The results show the ability of the model to predict the response of the anchors and the suitability of the $\mathrm{AE}$ method to monitor damage onset and propagation and to discriminate among different source of damage. DOI: 10.1061/(ASCE)EM.1943-7889.0000288. @ 2011 American Society of Civil Engineers.
\end{abstract}

CE Database subject headings: Pullout; Finite element method; Structural health monitoring; Elastoplasticity; Experimentation; Validation.

Author keywords: Pullout test; Acoustic emission; Finite elements; Structural health monitoring; Elastoplasticity.

\section{Introduction}

The recent collapse of a portion of a concrete ceiling at the Interstate 90 connector tunnel in Boston [National Transportation Safety Board (NTSB) 2007] because of poor creep resistance of the epoxy resin of an epoxy adhesive anchor systems and the occasional roof collapses in mines demonstrate the importance of epoxy adhesive anchor system in the field of civil engineering.

This paper presents the results of a numerical and experimental validation of the elastoplastic damaging model presented in the companion paper (Part I). The validation was conducted by studying the pullout strength of rebar embedded in a hardened concrete cylinder by means of polyester resin. The pullout test is a standard experimental procedure to evaluate the bond strength between steel/concrete or steel/adhesive/concrete interfaces. Although several analytical, numerical, and experimental studies were conducted on steel/concrete interaction, the same cannot be said of the steel/ adhesive/concrete system. The theoretical model is implemented in a new finite-element subroutine interfaced with the finite-element code FEAP (Taylor 2005a, b).

The numerical results were validated by experimental tests. Each test consisted of a rebar chemically bonded to a hardened

\footnotetext{
${ }^{1}$ Postdoctoral Scholar, Dept. of Civil, Environmental, and Aerospace Engineering, Univ. of Palermo, Viale delle Scienze-Ed. 8-90128, Palermo, Italy.

${ }^{2}$ Assistant Professor, Laboratory for Nondestructive Evaluation and Structural Health Monitoring Studies, Dept. of Civil and Environmental Engineering, Univ. of Pittsburgh, 942 Benedum Hall, 3700 O'Hara Street, Pittsburgh, PA 15261 (corresponding author). E-mail: pir3@pitt.edu

${ }^{3}$ Professor, Dept. of Civil, Environmental, and Aerospace Engineering, Univ. of Palermo, Viale delle Scienze-Ed. 8-90128, Palermo, Italy.

Note. This manuscript was submitted on August 13, 2010; approved on June 18, 2011; published online on June 21, 2011. Discussion period open until May 1, 2012; separate discussions must be submitted for individual papers. This paper is part of the Journal of Engineering Mechanics, Vol. 137, No. 12, December 1, 2011. CASCE, ISSN 0733-9399/2011/ $12-862-876 / \$ 25.00$.
}

concrete cylinder by means of polyester resin. The embedment was designed to yield to shear pullout failure. The tests were monitored by the nondestructive evaluation method of acoustic emission (AE), which exploits the propagation of transient elastic waves generated by the rapid release of energy from a localized source or sources within a material. One the primary advantages of $\mathrm{AE}$ is its capability to identify the location and origin of the transient waves being detected. As such, in this study, AE was used to validate the type of failure predicted by the analytical and numerical models.

Several studies exist on AE applied to pullout tests in bar/ concrete systems (Balázs et al. 1996; Fink 2001; Grosse et al. 2003; Köppel and Grosse 2000). For instance, Balázs et al. (1996) discussed AE results obtained in monotonic loading, cyclic loading, and long-term loading of rebars embedded in concrete cubes and subjected to a pullout load. However, to the best of the authors' knowledge no AE studies were conducted on chemically bonded bar/concrete systems subjected to pullout.

In this study, $\mathrm{AE}$ results were analyzed by means of parameter analysis (Rizzo and Lanza di Scalea 2001; Lavrov 2001; Gostautas et al. 2005; Matta et al. 2006; Ranjith et al. 2008; Degala et al. 2009; Rizzo et al. 2010) and moment tensor analysis (Landis and Shah 1993; Ohtsu 1995; Suaris and van Mier 1995; Guo et al. 1997; Chang and Lee 2004; Ohno et al. 2007; Rizzo et al. 2010). The advantage of the first analysis is that it can be conducted by using one sensor only. The moment tensor analysis instead requires the use of at least six sensors and can provide useful information about the mode and orientation of cracks.

The novel contribution of this paper is threefold: the elastoplastic damaging model recently introduced (Spada et al. 2009) is applied for the first time to postinstalled, chemically bonded anchors; AE is used to monitor the onset and propagation of cracks in chemically bonded bar/concrete structures, and therefore it is proposed to prevent catastrophic events, such as the one described in NTSB (2007); finally, the use of AE to validate the analytical and numerical model represents another element of novelty of this study. 


\section{Acoustic Emission}

For the sake of completeness, a brief overview of the principles underlying $\mathrm{AE}$ and the algorithms used for the analysis are provided. An AE is defined as the transient elastic wave generated by the rapid release of energy from a localized source or sources within a material. The elastic energy propagates as a stress wave (AE event) in the structure and is detected by one or more $\mathrm{AE}$ sensors. AE events may be generated by, for example, moving

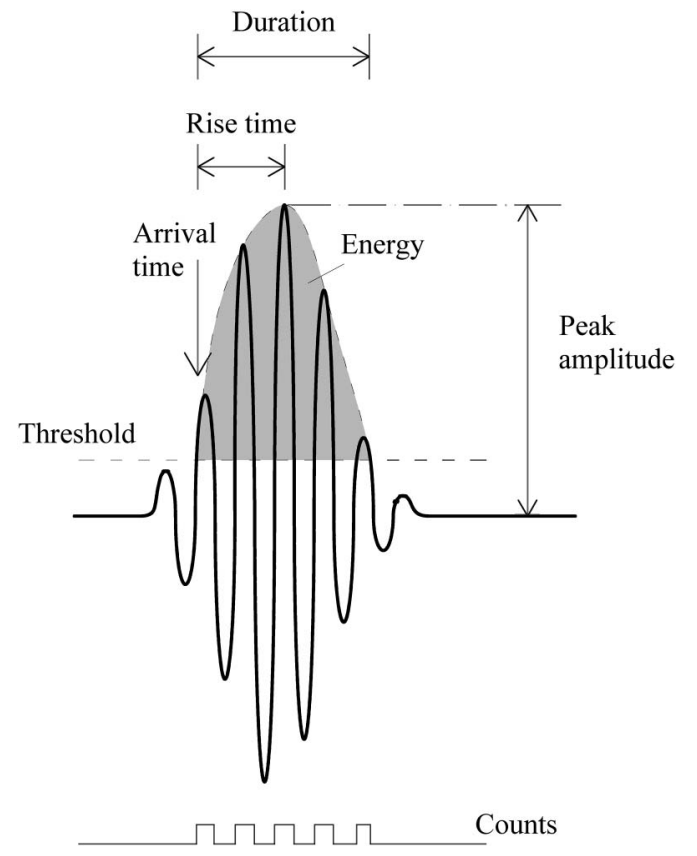

Fig. 1. Primary characteristics of an AE wave

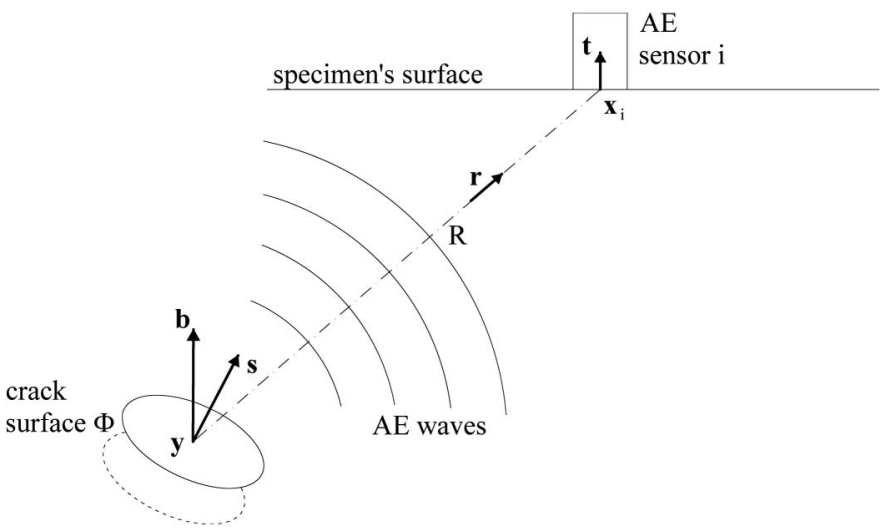

Fig. 2. Formation, propagation, and acquisition of an $\mathrm{AE}$ wave dislocations, crack onset growth and propagation, fiber breaks, disbonds, and plastic deformation. (Degala et al. 2009). Similar to seismology, elastic waves originate from a source inside the material and travel through the material, and they can be recorded by a set of sensors distributed on the external surface of the specimen.

AE differs from other nondestructive evaluation methods in two ways. First, the signal has its origin in the material itself and is not introduced from an external source. Second, AE detects movement or strain, whereas most other methods detect existing geometric discontinuities or breaks (Shull 2002). One of the primary objectives of the AE technique is to discriminate among different sources of damage; thereby attributing each emission to a particular source type or failure mode. One or more analyses can be carried out to address this objective.

The conventional parameter analysis of an AE event evaluates AE features such as counts, amplitude, rise time, and energy (Fig. 1). These parameters are then correlated to the mechanical/ structural event that generated the event. Other methods, such as the moment tensor analysis (Ohtsu 1995; Ohno and Ohtsu 2010), " $b$-value analysis" (Colombo et al. 2003; Schumacher et al. 2011), improved $b$-value (Shiotani et al. 1994; Aggelis et al. 2010), and the moment tensor inversion method (Grosse et al. 2003) or advanced signal processing linked to wavelet transforms (Mizutani et al. 2000; Qi 2000), neural networks (Chen and Wissawapaisal 2000; Huguet et al. 2002) have been proposed.

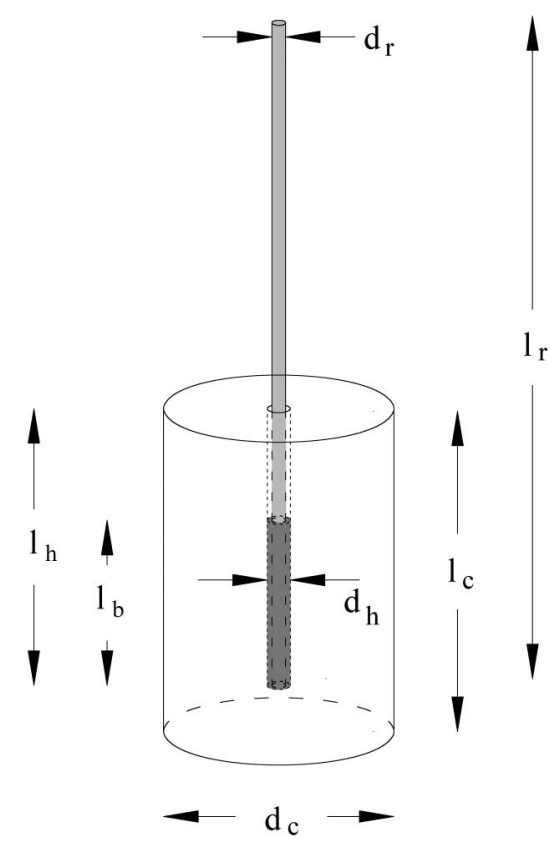

Fig. 3. Geometric characteristics of the specimens

Table 1. Cylinder and Hole Geometry and Main Test Data

\begin{tabular}{lccccccc}
\hline Test number & $l_{c}(\mathrm{~mm})$ & $d_{c}(\mathrm{~mm})$ & $d_{h}(\mathrm{~mm})$ & $l_{h}(\mathrm{~mm})$ & $l_{b}(\mathrm{~mm})$ & Displacement rate time $(\mathrm{mm} / \mathrm{s})$ & Peak load $(\mathrm{kN})$ \\
\hline 1 & 357.6 & 243.6 & 26.43 & 306.3 & 152.4 & 0.052 & 0.057 \\
2 & 358.6 & 244.6 & 26.39 & 304.8 & 152.4 & 0.051 & 84.5 \\
3 & 359.2 & 255.3 & 26.54 & 309.6 & 152.4 & 0.031 & 0.041 \\
4 & 357.9 & 243.6 & 26.77 & 309.6 & 101.6 & 0.039 & 28.9 \\
5 & 359.6 & 255.5 & 26.45 & 309.6 & $203.2+76.2$ & 144.2 \\
6 & 365.0 & 240.0 & 26.47 & 308.1 & 101.6 & 59.1 \\
\hline
\end{tabular}




\section{Source Localization}

The localization of an $\mathrm{AE}$ source can be determined by comparing the differences between the time of arrival of the elastic waves at the sensors. In bulk geometries, longitudinal waves (p-waves) and shear waves (s-waves) can propagate. Because p-waves are faster than s-waves, they are usually utilized to identify the location of an AE event.

Assuming that a certain structure is monitored by using $n \mathrm{AE}$ transducers, the estimate of the time of arrival $t_{s, i}$ of the p-wave at the sensor $i(i=1, \ldots, n)$ can be estimated by using the following equation:

$$
t_{s, i}=\frac{\left|\mathbf{x}_{s, i}-\mathbf{y}\right|}{v_{p}}+T=\frac{\sqrt{\left(x_{s, i}-x\right)^{2}+\left(y_{s, i}-y\right)^{2}+\left(z_{s, i}-z\right)^{2}}}{v_{p}}+T
$$

where $\mathbf{x}_{s, i}=\left(x_{s, i}, y_{s, i}, z_{s, i}\right)=$ position vectors of sensor $i ; \mathbf{y}=$ $(x, y, z)=$ position vector of the AE source; $v_{p}=$ velocity of the longitudinal bulk wave; and $T$ identifies the instant at which the release of transient energy occurred. Eq. (1) assumes that the wave velocity is independent of the direction of propagation and that the wave is not dispersive. In Eq. (1) the positions of the sensors are known, and the arrival time $t_{s i}$ is measured. Because Eq. (1) contains
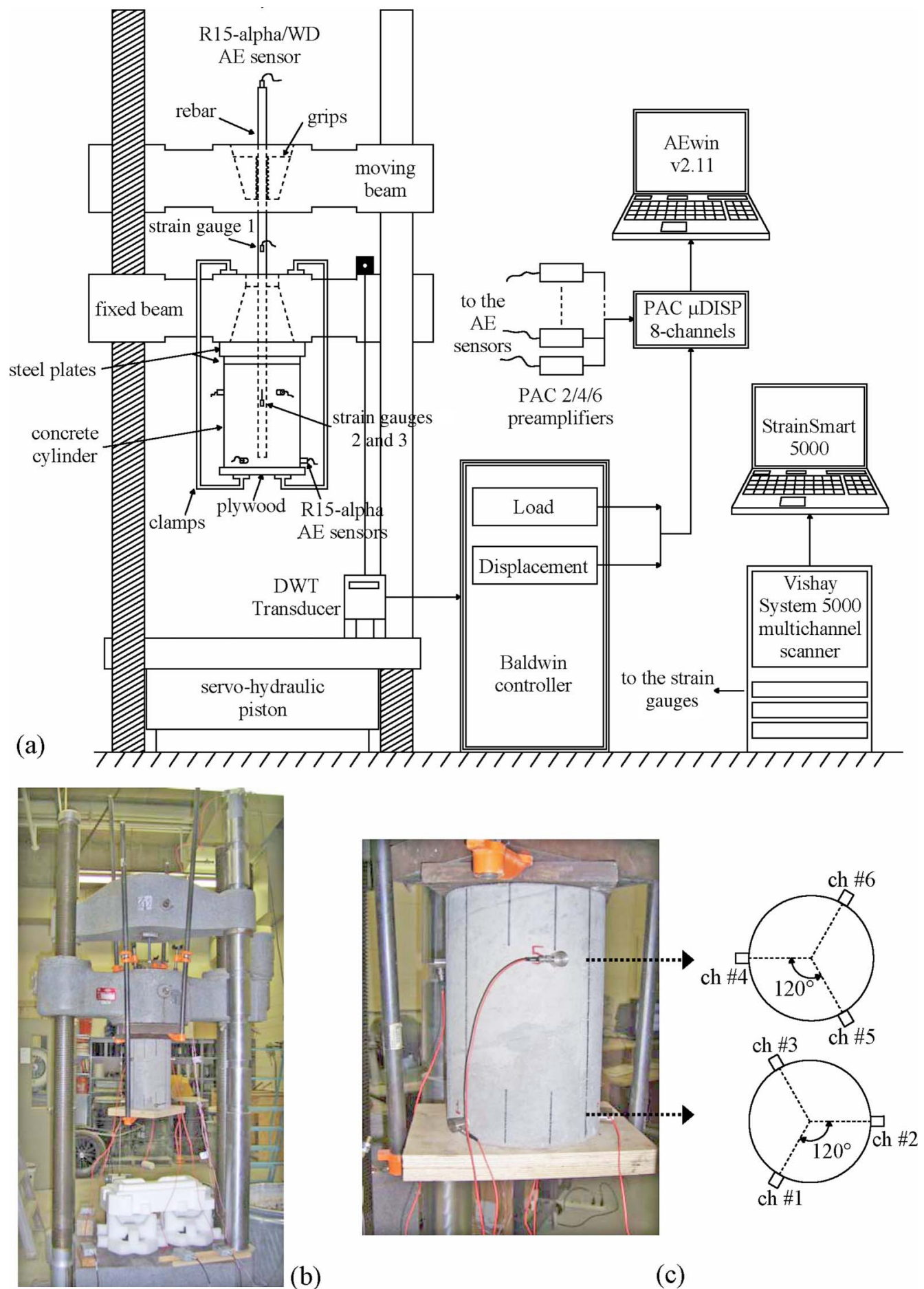

(b)

(c)

Fig. 4. Test setup: (a) schematic view; (b) specimen and instrument positioning; (c) R15-alpha acoustic emission sensors' installation on concrete (images by A. Spada) 
four unknowns, the source coordinates, and the instant $T$, at least four sensors are necessary. When more than four sensors are installed, the problem is overdetermined, but the result is more accurate. A system made by a series of Eq. (1) constitutes a nonlinear problem.
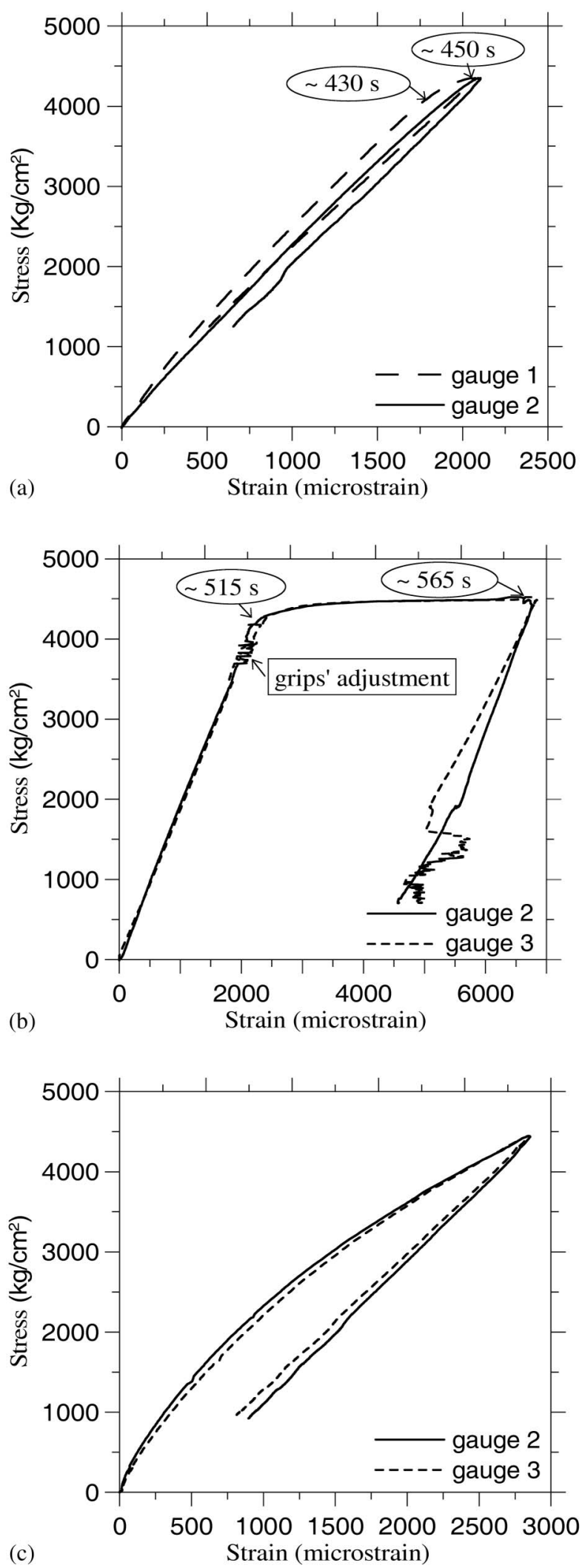

Fig. 5. Strain gauges results: (a) Test 1; (c) Test 2; (c) Test 3
In this study the solution of Eq. (1) was found by applying the Levenberg-Marquardt method, which is a nonlinear, least-squares approach (Press et al. 1992). This approach uses an iteration algorithm in which the estimation of the solution is computed by minimizing the errors of the unknown parameters.

\section{Moment Tensor Analysis}

The moment tensor analysis was used to determine the orientation, direction, and volume of cracks generated during the pullout tests. Specifically, the simplified Green's function for moment tensor analysis (SiGMA) proposed by Ohtsu (1995) was applied.

Consider a crack motion vector $\mathbf{b}(\mathbf{y}, t)$ at a point $\mathbf{y}$ and an instant $t$ of a fracture surface $\Phi$ with normal vector $\mathbf{s}$, as depicted in Fig. 2 . When $\mathbf{b}$ is parallel to $\mathbf{s}$, a tensile crack is propagating. Conversely, when $\mathbf{b}$ is orthogonal to $\mathbf{s}$, a shear crack is generated. Because vector $\mathbf{b}$ is time-dependent, its variation with time generates an elastic wave $\mathbf{u}_{i}\left(\mathbf{x}_{i}, t\right)$ that can be detected by AE transducers (Ohtsu 1995). If $\mathbf{b}(\mathbf{y}, t)$ is decomposed as

$$
\mathbf{b}(\mathbf{y}, t)=b(\mathbf{y}) \mathbf{l} S(t)
$$

with $\mathbf{I}=$ unit vector of the crack motion; $b(\mathbf{y})=$ magnitude of the crack displacement at point $\mathbf{y}$; and $S(t)=$ source time function of crack motion, then the theoretical waveform at sensor $i$ can be written as follows:

$$
\mathbf{u}_{i}\left(\mathbf{x}_{i}, t\right)=\int_{\Phi} G_{i p, q}\left(\mathbf{x}_{i}, \mathbf{y}, t\right) C_{p q k l} b(\mathbf{y}) l_{k} n_{l} * S(t) d \Phi
$$

where $G_{i p, q}=$ spatial derivative of Green's function; $C_{p q k l}=$ elastic constants of the material; and the symbol $*$ represents the convolution integral. Assuming the following:

$$
m_{p q}=C_{p q k l} l_{k} n_{l} \Delta V
$$

with

$$
\Delta V=\int_{\Phi} b(\mathbf{y}) d \Phi
$$

as the crack volume, Eq. (3) can be rewritten as

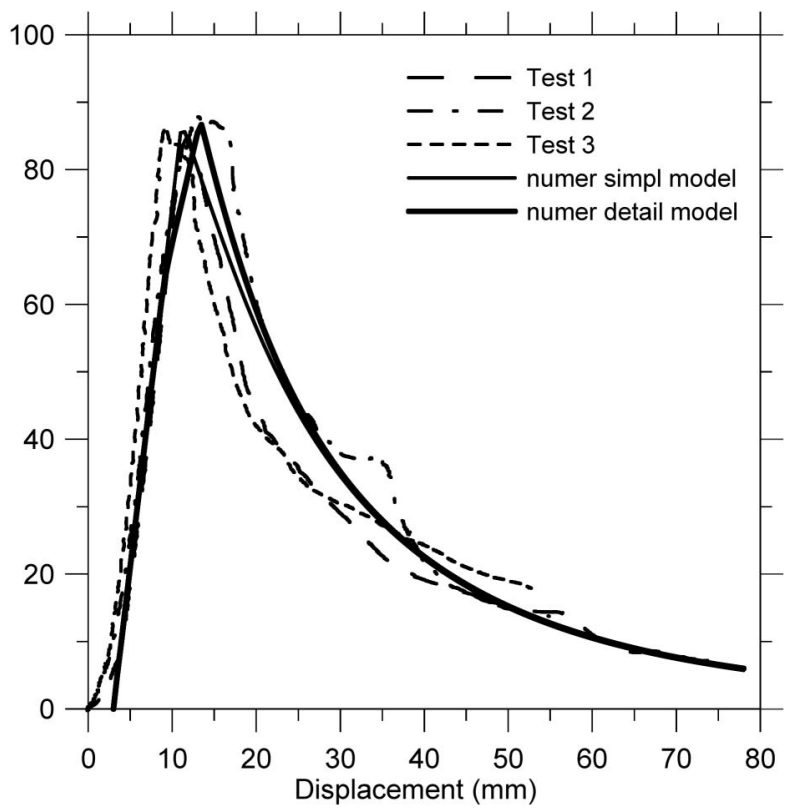

Fig. 6. Comparison of numerical and experimental results for $152.4 \mathrm{~mm}$ (6 in) bonded length 

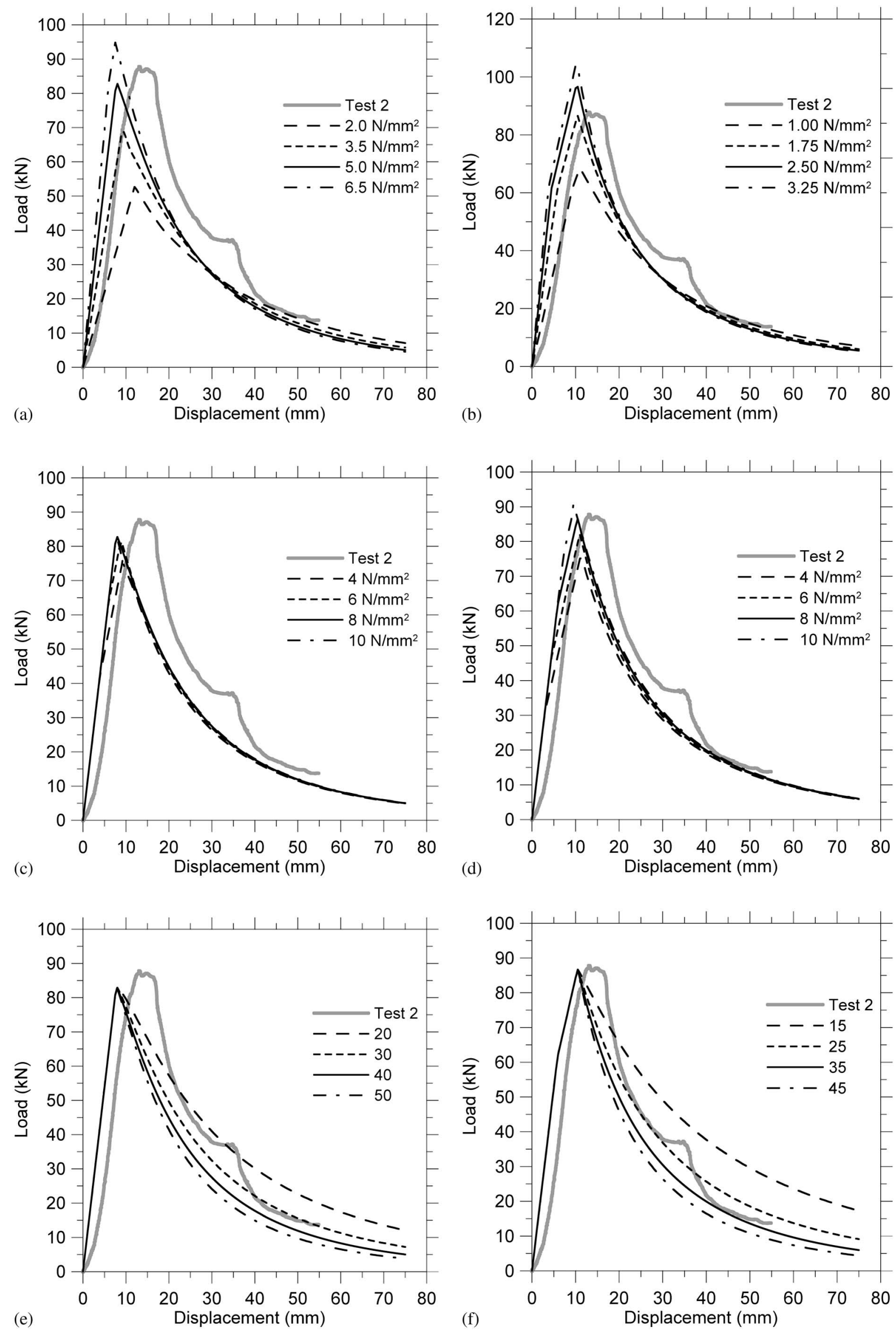

Fig. 7. Parametric analysis for the numerical micromodels: (a) shear modulus $G$ simplified model; (b) shear modulus $G$ detailed model; (c) cohesion $c_{0}$ simplified model; (d) cohesion $c_{0}$ detailed model; (e) parameter $c$ simplified model; (f) parameter $c$ detailed model 


$$
\mathbf{u}_{i}\left(\mathbf{x}_{i}, t\right)=G_{i p, q}\left(\mathbf{x}_{i}, \mathbf{y}, t\right) m_{p q} * S(t)
$$

where $m_{p q}$ is called the moment tensor. The elements $m_{p q}$ of the tensor are the product of a volume by a stress, and therefore, they have the unit of a moment.

In the SiGMA approach, only the amplitude of the first cycle of the AE waveform is considered. Thus, Eq. (6) is simplified as follows (Chang and Lee 2004):

$A(\mathbf{x})=\frac{C_{s} \operatorname{Ref}(\mathbf{t}, \mathbf{r})}{R}\left(\begin{array}{lll}r_{1} & r_{2} & r_{3}\end{array}\right)\left(\begin{array}{lll}m_{11} & m_{12} & m_{13} \\ m_{21} & m_{22} & m_{23} \\ m_{31} & m_{32} & m_{33}\end{array}\right)\left(\begin{array}{c}r_{1} \\ r_{2} \\ r_{3}\end{array}\right)$

where $A(\mathbf{x})=$ amplitude of the first motion; $C_{s}=$ calibration coefficient of the sensor; and $\operatorname{Ref}(\mathbf{t}, \mathbf{r})=$ reflection coefficient between vector $\mathbf{t}$ and vector $\mathbf{r}$. As shown in Fig. 2, the vector $\mathbf{t}$ is the direction of $\mathrm{AE}$ sensor sensitivity, whereas the vector $\mathbf{r}$ represents the unit vector that identifies the wave propagation line from the source to the sensor, separated by the distance $R$.
In Eq. (7) vector $\mathbf{t}$ and the waveform amplitudes recorded at each sensor are known. If the $\mathrm{AE}$ transducers used for the localization are identical, i.e., they possess the same sensitivity, then the coefficient $C_{s}$ can be neglected. The moment tensor $m_{p q}$ is symmetric, and only six elements are independent. The distance $R$ and the vector $\mathbf{r}$ are known after source localization. Therefore, Eq. (7) has six unknowns, and at least six sensors are needed to calculate the elements $m_{p q}$.

Once the elements $m_{p q}$ are determined, the eigenvalue analysis of the moment tensor is performed. This analysis yields to the determination of the crack type, orientation, and direction. From the tensor eigenvalues $\lambda_{1}, \lambda_{2}$, and $\lambda_{3}$, with $\lambda_{1}>\lambda_{2}>\lambda_{3}$, the values of the shear ratio $X$, deviatoric tensile ratio $Y$, and isotropic tensile ratio $Z$ can be calculated by solving the following system:

Table 2. Parameters Used for Tests in Fig. 7

\begin{tabular}{|c|c|c|c|c|c|c|c|c|}
\hline & Figure & $G_{A}=G_{F}\left(\mathrm{~N} / \mathrm{mm}^{2}\right)$ & $E_{A}=E_{F}\left(\mathrm{~N} / \mathrm{mm}^{2}\right)$ & $c_{0}\left(\mathrm{~N} / \mathrm{mm}^{2}\right)$ & $\varsigma_{0}(\mathrm{~N} / \mathrm{mm})$ & $h_{p}\left(\mathrm{~N} / \mathrm{mm}^{3}\right)$ & $p$ & $c$ \\
\hline \multirow[t]{11}{*}{ Simplified micromodel } & \multirow[t]{4}{*}{$7(\mathrm{a})$} & 2.0 & 5.0 & \multirow[t]{4}{*}{8.0} & \multirow[t]{4}{*}{30} & \multirow[t]{4}{*}{1.5} & \multirow[t]{4}{*}{5} & \multirow[t]{4}{*}{40} \\
\hline & & 3.5 & 8.75 & & & & & \\
\hline & & 5.0 & 12.5 & & & & & \\
\hline & & 6.5 & 16.3 & & & & & \\
\hline & \multirow[t]{4}{*}{$7(\mathrm{c})$} & \multirow[t]{4}{*}{5.0} & \multirow[t]{4}{*}{12.5} & 4.0 & \multirow[t]{4}{*}{30} & \multirow[t]{4}{*}{1.5} & \multirow[t]{4}{*}{5} & \multirow[t]{4}{*}{40} \\
\hline & & & & 6.0 & & & & \\
\hline & & & & 8.0 & & & & \\
\hline & & & & 10.0 & & & & \\
\hline & \multirow[t]{3}{*}{$7(e)$} & \multirow[t]{3}{*}{5.0} & \multirow[t]{3}{*}{12.5} & \multirow[t]{3}{*}{8.0} & \multirow[t]{3}{*}{30} & \multirow[t]{3}{*}{1.5} & \multirow[t]{3}{*}{5} & 20 \\
\hline & & & & & & & & 30 \\
\hline & & & & & & & & 50 \\
\hline \multirow{15}{*}{$\begin{array}{l}\text { Detailed micromodel } \\
\text { rebar/resin interface }\end{array}$} & \multirow[t]{4}{*}{$7(b)$} & 1.0 & 2.5 & \multirow[t]{4}{*}{8.0} & \multirow[t]{4}{*}{40} & \multirow[t]{4}{*}{1.5} & \multirow[t]{4}{*}{5} & \multirow[t]{4}{*}{35} \\
\hline & & 1.75 & 4.38 & & & & & \\
\hline & & 2.5 & 6.25 & & & & & \\
\hline & & 3.25 & 8.13 & & & & & \\
\hline & \multirow[t]{4}{*}{$7(d)$} & \multirow[t]{4}{*}{1.75} & \multirow[t]{4}{*}{4.38} & 4.0 & 40 & 1.5 & 5 & 35 \\
\hline & & & & 6.0 & & & & \\
\hline & & & & 8.0 & & & & \\
\hline & & & & 10.0 & & & & \\
\hline & $7(e)$ & 1.75 & 4.38 & 8.0 & 40 & 1.5 & 5 & 15 \\
\hline & & & & & & & & 25 \\
\hline & & & & & & & & 35 \\
\hline & & & & & & & & 45 \\
\hline & Detailed micromodel: & 5.25 & 13.1 & 24.9 & 120 & 4.5 & 5 & 35 \\
\hline & Values at & & & & & & & \\
\hline & resin/concrete interface & & & & & & & \\
\hline
\end{tabular}

Table 3. Parameters Used for Numerical Tests after Calibration

\begin{tabular}{|c|c|c|c|c|c|c|c|}
\hline Location & $G_{A}=G_{F}\left(\mathrm{~N} / \mathrm{mm}^{2}\right)$ & $E_{A}=E_{F}\left(\mathrm{~N} / \mathrm{mm}^{2}\right)$ & $c_{0}\left(\mathrm{~N} / \mathrm{mm}^{2}\right)$ & $\varsigma_{0}(\mathrm{~N} / \mathrm{mm})$ & $h_{p}\left(\mathrm{~N} / \mathrm{mm}^{3}\right)$ & $p$ & $c$ \\
\hline Simplified micromodel & 5.0 & 12.5 & 8.3 & 32.4 & 1.5 & 5 & 40 \\
\hline Detailed micromodel rebar/resin interface & 1.75 & 4.38 & 8.3 & 40 & 1.5 & 5 & 35 \\
\hline Detailed micromodel resin/concrete interface & 5.25 & 13.1 & 24.9 & 120 & 4.5 & 5 & 35 \\
\hline
\end{tabular}


When $X>60 \%$ the crack is referred to as a shear crack; when $X<40 \%$ and contemporary $Y+Z>60 \%$, instead, sources are referred to as tensile cracks; finally, if $40<X<60 \%$, the source is considered a mixed crack (Ohtsu 1995; Chang and Lee 2004).

The computation of the eigenvectors $\mathbf{e}_{1}, \mathbf{e}_{2}$, and $\mathbf{e}_{3}$ with $\mathbf{e}_{1}<$ $\mathbf{e}_{2}<\mathbf{e}_{3}$ yields to the determination of the unit crack motion vector and the unit crack normal vector by means of the following system:

$$
\left\{\begin{array}{l}
\mathbf{e}_{1}=\mathbf{l}+\mathbf{s} \\
\mathbf{e}_{2}=\mathbf{l} \times \mathbf{s} \\
\mathbf{e}_{3}=\mathbf{l}-\mathbf{s}
\end{array}\right.
$$

where $x$ is the vector product.

\section{Model Validation}

\section{Test Specimens}

Six concrete cylinders were cast using a mix proportion of 1:2:3.22 by weight of portland cement, natural sand, and \#57 limestone. The water/cement ratio was equal to 0.4 . The cylinders were $254 \mathrm{~mm}$ (10 in.) in diameter and $355.6 \mathrm{~mm}$ (14 in.) high. The concrete cured for 28 days at ambient temperature.

The density, Young's modulus, Poisson's ratio, and compressive strength of concrete were measured according to ASTM C469 (ASTM 1994) and ASTM C39 (ASTM 2001). Compressive tests were performed on two 101.6 by $203.2 \mathrm{~mm}$ (4 by 8 in.) cylindrical specimens cured in water for 35 days, weighted and capped, according to the ASTM C617 (ASTM 1998). The tests determined the following average values: density equal to $2.3 \times 10^{-5} \mathrm{~N} / \mathrm{mm}^{3}$, Young's modulus of 21,197 MPa, Poisson's ratio of 0.16 , and compressive strength equal to $46.25 \mathrm{MPa}$.

The steel rebar consisted of a \#5 $\left(1.98 \mathrm{~mm}^{2}\right)$ section, 1,219.2 mm (4 ft.) long with moon-shaped cross ribs and longitudinal ribs. The nominal yielding and ultimate forces were $84.4 \mathrm{kN}$ (18.6 kips) and $126.6 \mathrm{kN}$ (27.9 kips), respectively.

After 28 days of curing time, each cylinder was drilled to create a $25.4 \mathrm{~mm}$ (1 in.) diameter hole, $304.8 \mathrm{~mm}$ (12 in.) deep. Every hole was flushed with water to remove dust. Once the holes were dry, a rebar was anchored in the concrete by using Minova Lokset polyester resin.

The geometric characteristics of the six specimens are summarized in Table 1 and schematized in Fig. 3. Each rebar was instrumented with three strain gauges. Two were located in the proximity of the bond, and one was in the middle of the rebar. The pullout test was performed after $24-27 \mathrm{~h}$ of the embedment.

\section{Test Setup}

The specimens were tested in a universal Baldwin servohydraulic machine with ultimate tensile capacity of $907 \mathrm{kN}$ (200 kips), operated in displacement control. A schematic view of the whole test setup is shown in Fig. 4(a).

The cylinders were clamped to the fixed lower cross beam of the machine [Figs. 4(a) and 4(b)]. Two square steel plates were positioned between the cylinder and the cross beam to center the bar and provide a uniform, distributed stress on the top surface of the concrete. The relative displacement between the two cross beams was measured by a draw wire transducer (DWT) with $0.1 \mathrm{~mm}$ resolution. The strain gauges' measurements were acquired every second by a Vishay System 5000 multichannel scanner using the software StrainSmart 5000.

The AE instrumentation suite consisted of the following: (1) broadband AE piezoelectric transducers (Physical Acoustics

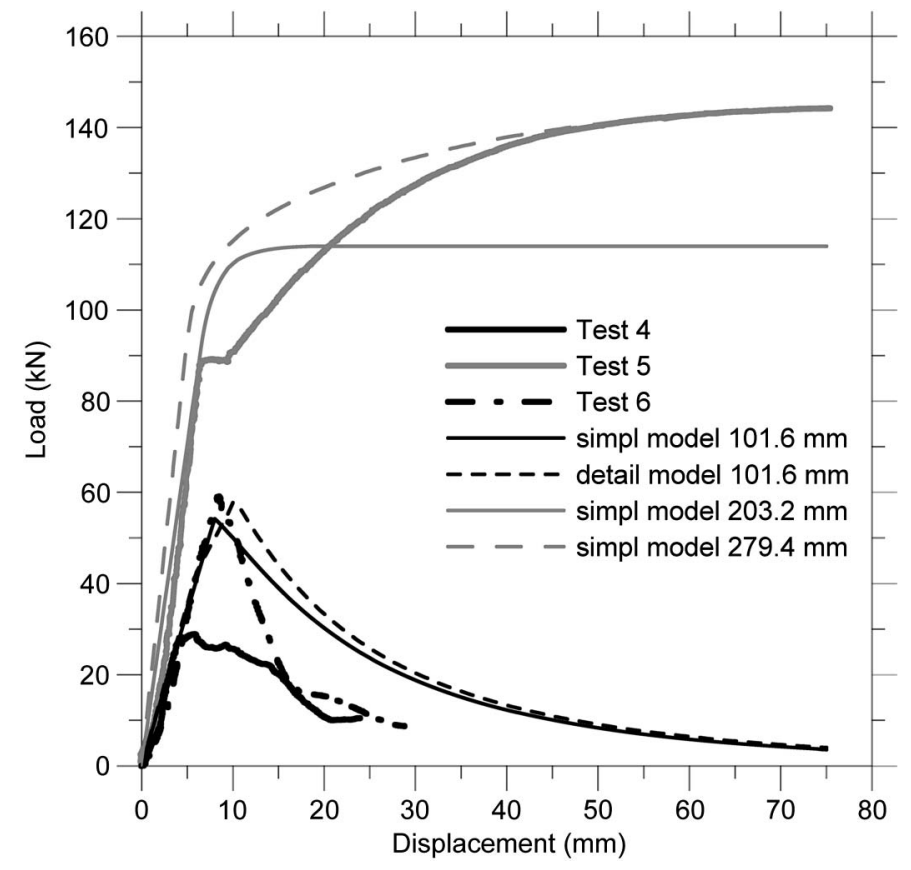

Fig. 8. Comparison of numerical and experimental results for Tests 4-6
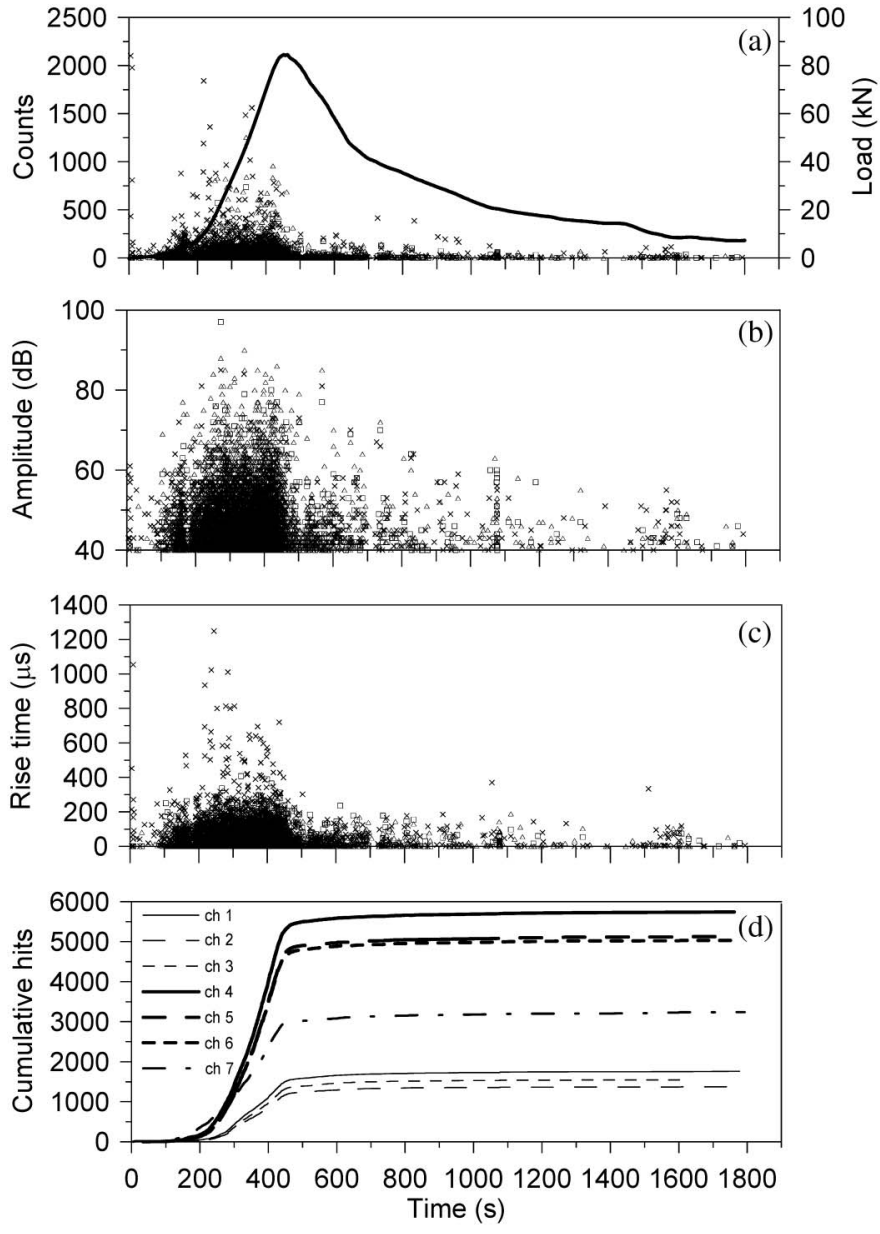

Fig. 9. Test 1 -parametric analysis results: (a) counts; (b) amplitude; (c) rise time; (d) cumulative hits; square $(\square)=$ Channel 1; triangle $(\Delta)=$ Channel 4; $\operatorname{cross}(x)=$ Channel 7 
R15-alpha and WD transducers) used in conjunction with preamplifiers set at a $40 \mathrm{~dB}$ gain; (2) an eight-channel high-speed Physical Acoustics $\mu$ DiSP data acquisition board; and (3) a laptop with dedicated AEwin v2.11 software for signal processing and storage. The values of the applied load and of the DWT measurement were collected through the AE data acquisition system.

Before the tests, transducer positioning, signal threshold settings, and sensor sensitivity were determined by using the traditional pencil lead break test. The threshold level was set at $40 \mathrm{~dB}$. The sampling rate was chosen as $5 \mathrm{MHz}$. Six R15 transducers were attached to the concrete cylinders and positioned at two different plane levels. The position of the sensors is schematized in Fig. 4(c). One sensor was attached to the cross section end of the rebar. Every transducer was attached by using hot melting glue. To account for the different properties of steel and concrete, the value of peak definition time (PDT), hit definition time (HDT), and hit locking time (HLT) were chosen differently; namely, PDT $=42 \mu \mathrm{s}$, $\mathrm{HDT}=134 \mu \mathrm{s}, \mathrm{HLT}=300 \mu \mathrm{s}$ for concrete, and PDT $=300 \mu \mathrm{s}$, $\mathrm{HDT}=600 \mu \mathrm{s}, \mathrm{HLT}=1,000 \mu \mathrm{s}$ for steel.

\section{Numerical and Experimental Results}

The stress-strain curves obtained from the strain gauges during Tests 1-3 are presented in Fig. 5. As described in Table 1, the bond length for these tests was equal to $152.4 \mathrm{~mm}$ (6 in.). Fig. 5 shows that the rebars used in Tests 1 and 2 yielded. The instants at which yielding and debonding occurred are indicated. The rebar adopted in Test 3 showed nonlinear behavior during the pullout. Such a response was probably attributable to a slight eccentricity generated during the embedment process. It must be reported that Gauge 3 in Test 1 and Gauge 1 in Tests 2 and 3 were lost during the anchoring of the rebar.

At the end of the test, the ribs were clearly visible, and it was determined that debonding occurred at the rebar/resin interface because of shear pullout failure. The load-displacement curves obtained from Tests 1-3 are shown in Fig. 6. The results of the finiteelement analysis are superimposed. The rebar is modeled as a Von Mises plastic material with an elastic limit of $418 \mathrm{MPa}$ and a slight hardening equal to $20 \mathrm{MPa}$.

Each experimental curve is characterized by initial nonlinear behavior due to the start-up and the adjustment of the grips of the loading machine, followed by the linear behavior typical of the linear elastic range. The onset of debonding occurred at approximately $85 \mathrm{kN}$. The tests were conducted until complete debonding was observed. The softening branch in Fig. 6 identifies damage onset and propagation. The structural response at softening is affected by the amount of damage occurring at the interface. In addition, as the rebar pulled out, the contact surface between the resin/rebar and the resin/concrete interface decreased. Such a
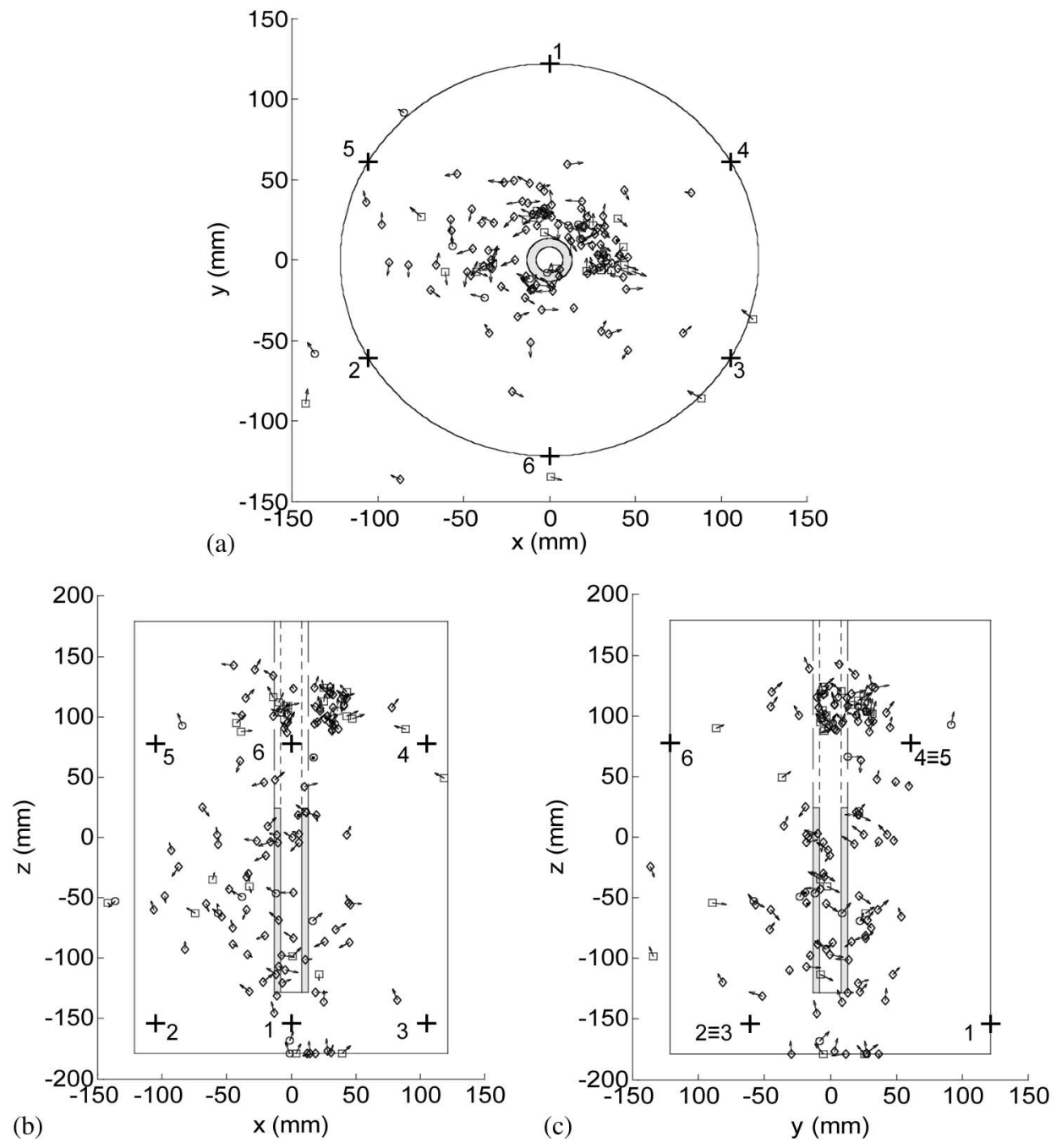

Fig. 10. Test 1 : (a) $x-y$; (b) $x-z$; (c) $y-z$ views of the moment tensor results; plus $(+)=$ sensor's position; diamond $(\diamond)=$ shear cracks; square $(\square)=$ tensile cracks; circle $(\bigcirc)=$ mixed cracks 
decrease reduced the friction force between the ribs and the surrounding material, affecting the force-displacement response of the structure at softening.

In Tests 1 and 3, the transition from the linear elastic to the softening regime was rapid. In Test 2 , however, a slight variation of the linear slope was visible at approximately $70 \mathrm{kN}$. This behavior was probably attributable to damage onset localized in a weak zone of the interface that failed before the occurrence of the main debonding.

The load-displacement results of Tests 1-3 were used to calibrate the parameters of both the simplified and the detailed numerical micromodel. Initially, it was assumed that the adhesive phase $A$
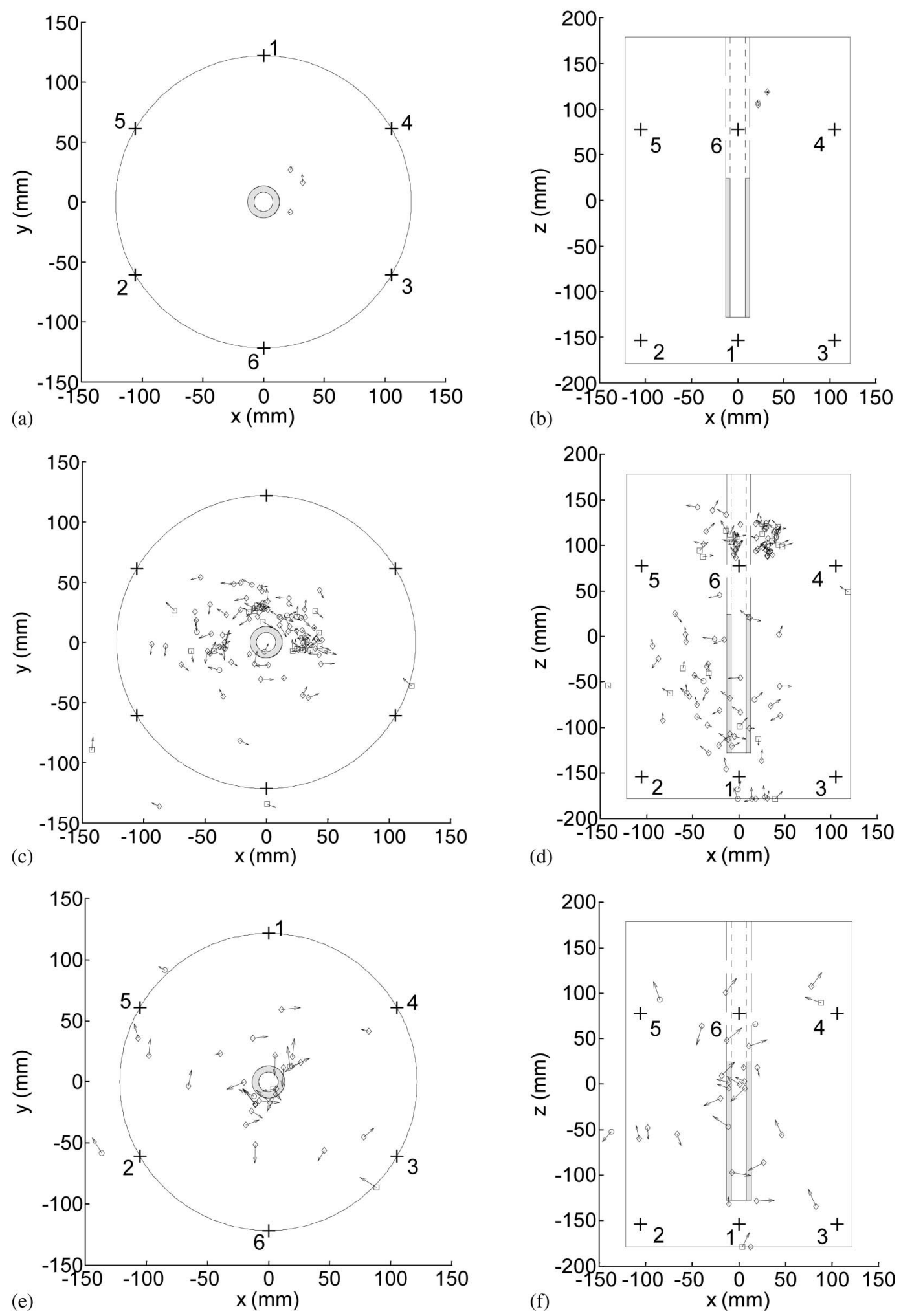

Fig. 11. Test 1 moment tensor results: (a) $0<T<200 \mathrm{~s} x$-y view; (b) $0<T<200 \mathrm{~s} x$ - $z$ view; (c) $200<T<450 \mathrm{~s} x-y$ view; (d) $200<T<450 \mathrm{~s}$ $x-z$ view; (e) $T>450 \mathrm{~s} x-y$ view; (f) $T>450 \mathrm{~s} x$ - $z$ view; plus $(+)=$ sensor's position; diamond $(\diamond)=$ shear cracks; square $(\square)=$ tensile cracks; circle $(\bigcirc)=$ mixed cracks 
and the frictional phase $F$ had the same mechanical characteristics. This implied that the values associated with both phases' Young's modulus, shear modulus, internal frictional angle, and dilatancy angle were the same. Owing to the shear pullout failure observed in Tests $1-3$, the shear modulus $G$ was considered as an independent variable, and the Young's modulus $E$ was calculated by using the classical relation

$$
G=\frac{E}{2(1+\nu)}
$$

where $\nu=$ Poisson's ratio.

No dilatancy effect was considered, which implies that $\mu_{A}=$ $\mu_{F}=0$, whereas the internal frictional angle was fixed equal to $\varphi_{A}=\varphi_{F}=30^{\circ}$. The Poisson's ratio was chosen equal to $\nu=0.25$ for the interfaces. Because shear failure is expected, the value of the tensile threshold $\sigma_{0}$ is not relevant. Finally, the damage threshold $\xi_{0}$ is chosen differently in the simplified and the detailed micromodels. In practice, it was decided that although damage and plasticity evolve together once the initial cohesion $c_{0}$ is reached in the simplified micromodel, in the detailed micromodel, a short branch with only plasticity is present before the damage is also activated.

Fifteen six-node rectangular-shaped elements were inserted into the simplified finite-element micromodel to implement the interface between rebar and concrete. The resin was included in the interface. In the detailed micromodel finite-element analysis, 15 six-node rectangular-shaped elements were used for the rebar/resin interface and the resin/concrete interface. For the calibrations of the parameters, a trial-and-error approach was followed. First, the shear elastic modulus of the interface was varied to determine a good agreement with the slope of the linear elastic range. In the same way, once the shear modulus was fixed, numerical analyses were carried out to find the initial cohesion $c_{0}$ for the simplified micromodel. Such a value was adopted for the detailed micromodel. Finally, the experimental data of the softening branch were utilized to estimate the parameter $h_{p}$ (plastic evolution) and the parameters $p$ and $c$ (damage evolution).

Because the detailed micromodel consists of two interfaces, two calibrations were necessary. However, because during Tests 1-3 the failure occurred at the rebar/resin interface, only the parameters associated with this interface can be calibrated. For the resin/concrete interface, an estimate of the parameters was made. The estimate consisted of the parameters associated with the rebar/resin interface multiplied by a scaling factor, which guaranteed the complete debonding at the rebar/resin interface with no significant movements in the rebar/concrete. The mechanical parameters $\left(E, G, h_{p}, c_{0}\right.$, and $\xi_{0}$ ) were multiplied by a factor equal to 3 .

Fig. 7 shows the load-displacement curves obtained from the numerical implementation for different values of the calibration parameters. The experimental result of Test 2 is superimposed. Figs. 7(a) and 7(b) show the load-displacement curve for different values of the shear modulus obtained by using the simplified micromodel and the detailed micromodel, respectively. Figs. 7(c) and 7(d) show the load-displacement curve for different values of the initial cohesion using the simplified micromodel and the detailed micromodel, respectively. Finally, Figs. 7(e) and 7(f) show the effect of the parameter $c$ for the evolution of damage.

The parameters used to run the analyses presented in Fig. 7 are summarized in Table 2, whereas Table 3 lists the values of the parameters chosen at the end of the simulation for the single interface of the simplified micromodel and for the two interfaces of the detailed micromodel.

The effect of the bond length on the structural response of the chemically bonded system anchor was investigated by using the values of the analytical parameters shown in Table 3 . The results are presented in Fig. 8, superimposed onto the experimental responses from Tests 4-6. As the bond length varied, the number of finite elements varied as well. For interfaces and resin, 10 finite elements were used to model the $101.6 \mathrm{~mm}$ (4 in.) bonded length, 20 elements were adopted to simulate the $203.2 \mathrm{~mm}$ ( 8 in.) bond, and 28 finite elements were used to simulate the $279.4 \mathrm{~mm}$ (11 in.) bond. The low pullout strength that occurred during Test 4 was probably caused by the reduced number of ribs along one side of the rebar and the improper mixing and distribution of the epoxy during the embedment.

The structural system with a bonding length of $101.6 \mathrm{~mm}$ (4 in.) denoted an experimental load peak $(59.11 \mathrm{kN}) 8.3 \%$ higher than the numerical peak observed by using the simplified model and $2.4 \%$ higher than the load peak observed adopting the detailed model. Both models overestimated the softening branch, although the overall trend was recognized.

The experimental results from Test 5 showed the typical loading pattern of a free rebar under a tensile load. Elastic, yielding, and hardening regions are clearly visible. The increase of the adhesive and frictional forces at the rebar/resin interface was associated with a much larger area of the resin/bar interface. In fact, a visual inspection conducted at the end of the test revealed that the effective length of the bond was $279.4 \mathrm{~mm}$ (11 in.), i.e., $76.2 \mathrm{~mm}$ (3 in.) of resin went on the epoxy-tape added to protect the strain gauges from the bond. Such a large interface area produced higher rigidity
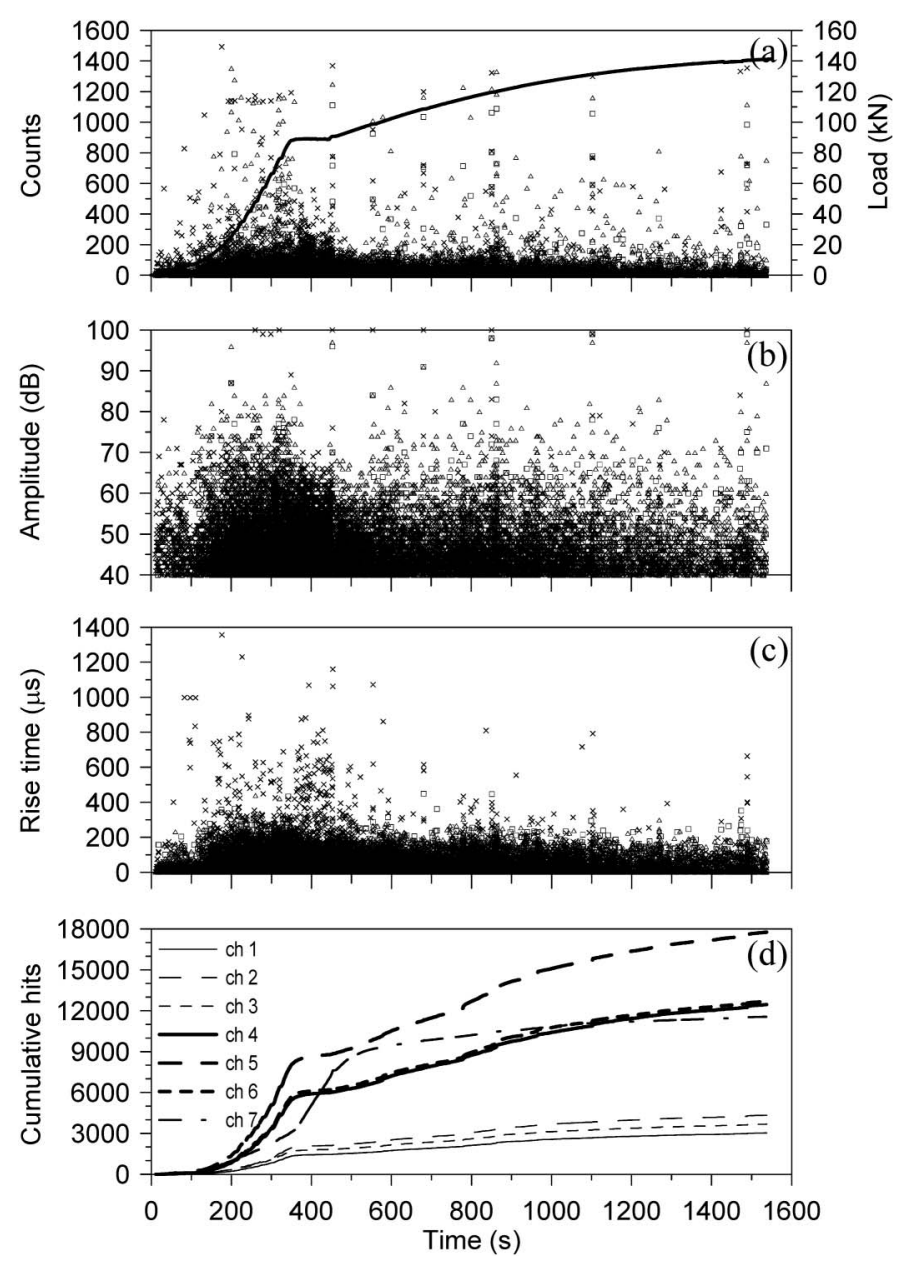

Fig. 12. Test 5 parametric analysis results: (a) counts; (b) amplitude; (c) rise time; (d) cumulative hits; square $(\square)=$ Channel 1; triangle $(\Delta)=$ Channel 4; $\operatorname{cross}(x)=$ Channel 7 
of the structure at the elastic region when compared with the $203.2 \mathrm{~mm}$ (8 in.) numerical case.

The structural response of the anchor with bond length equal to $203.2 \mathrm{~mm}$ (8 in.) and $279.4 \mathrm{~mm}$ (11 in.) was numerically computed for the simplified micromodel, and it is also presented in Fig. 8.

Overall, by observing the results presented in Figs. 6 and 8, it can be affirmed that the numerical analyses predict the experimental results in terms of rigidity and pullout peak load. The latter is accurate as long as the materials remain in the linear elastic region. The method is therefore effective to design anchors that fail due to shear pullout. By increasing the bond length and maintaining the identical material properties and models' parameters, it can be accurately established whether the structure fails due to shear pullout or due to steel yielding. Because the model's parameters were set on the basis of the experimental response of the first three tests, a very good agreement between the numerical and experimental results at softening was observed for the first three tests. Conversely, in Tests 4 and 6 , the numerical results overestimated the response of the structure, although the general trend was predicted.

\section{Acoustic Emission Results}

The AE results for Tests 1, 5, and 6 are presented here. For Test 1 , the cross-sectional end of the rebar was instrumented with a PAC-WD transducer, whereas in Tests 5 and 6, a PAC R15-alpha sensor was adopted.

Counts, amplitude, and rise time of the $\mathrm{AE}$ activity recorded by Sensors 1,4 , and 7 during Test 1 are plotted as functions of time in Figs. 9(a)-9(c). The applied load is superimposed on the counts' plot. The activity recorded during the first $200 \mathrm{~s}$ is associated with the adjustment of the grips and the friction between the rebar and
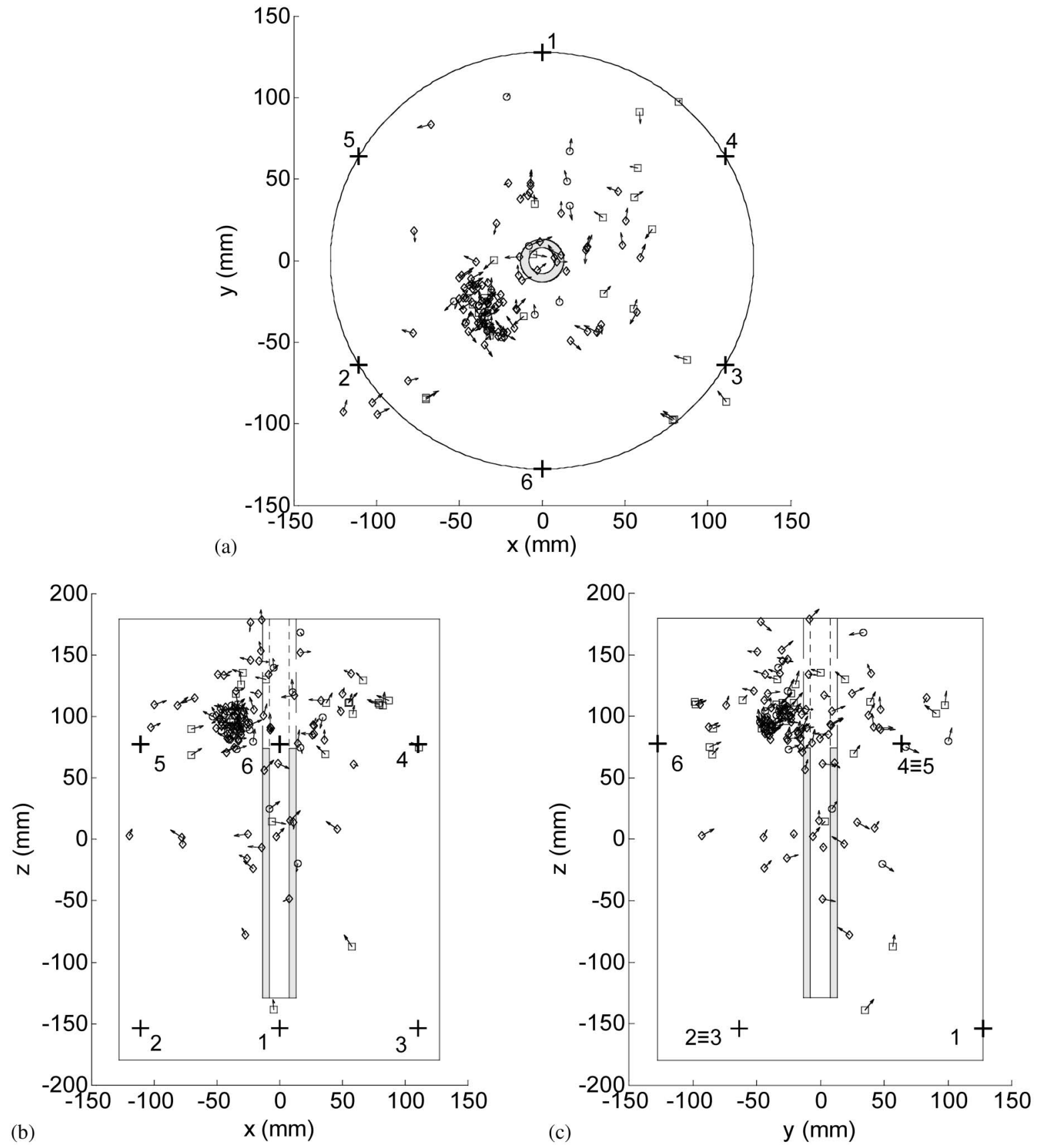

Fig. 13. Test 5: (a) $x-y$; (b) $x-z$; (c) $y-z$ views of the moment tensor results; plus $(+)=$ sensor's position; diamond $(\diamond)=$ shear cracks; square $(\square)=$ tensile cracks; circle $(\bigcirc)=$ mixed cracks 
the grips. This is demonstrated by the large activity registered by Channel 7 , attached to the free cross section of the rebar. The presence of such a friction is also confirmed by the cumulative hits' plot in Fig. 9(d), which shows that Sensor 7 recorded most of the activity within the first $200 \mathrm{~s}$.

In the elastic range, the AEs are generated by the rebar deformation, by the onset of the resin/rebar debonding, and in part due to the crushing and friction associated with the contact forces between the concrete and the steel plate utilized to provide a uniform distributed stress on the top of the concrete surface. The values of the AE amplitudes [Fig. 9(b)] are equally distributed over the three transducers under consideration; however, the values of counts [Fig. 9(a)] associated with Sensor 7 are higher than the values associated with the transducers attached to the concrete. This result is the consequence of the multiple reflections, the low energy attenuation occurring in the waveguide, and the different sensitivity of the WD transducer with respect to the R-15 transducers. Finally, Fig. 9(d) shows the number of cumulative hits as a function of time for every channel employed in the experiment. From 0-300 s, Channel 7 recorded the largest number of hits. After $300 \mathrm{~s}$, the largest number of activities was recorded by Channel 4 . This indicates that the interface area closer to Sensor 4 experienced the onset and propagation of the initial debonding.

When the peak load is reached, macrocracks appear at the rebar/ resin interface. The presence of these cracks decreases the pullout strength of the system. Because the presence of macrocracks reduces the contact area between the rebar and resin, a softening branch appeared beyond the peak load. Because at softening the value of the applied stress is below the peak value, the presence of the Kaiser effect excludes the generation of AE within the steel. Therefore, all the AE sources observed during the softening branch are localized at the rebar/resin interface and are related to a combination of debonding and frictional effects.

Fig. 10 shows the results of the moment tensor analysis for Test 1 . The following known relationship (Shull 2002) was used:

$$
v_{p}=\sqrt{\frac{E}{\rho}\left(\frac{1-\nu}{(1+\nu)(1-2 \nu)}\right)}
$$

In Eq. (11), $\rho=$ material's density; and $v_{p}=\mathrm{p}$-wave velocity. The value $v_{p}=3,133 \mathrm{~m} / \mathrm{s}$ was adopted in this study. The moment tensor source locations in the $x-y, x-z$, and $y-z$ planes are presented in Figs. 10(a)-10(c), respectively. Shear, tensile, and mixed cracks are identified; a prevalence of shear cracks is present. The arrows indicate the unit crack motion vectors. Overall, the largest amount of cracks was localized around the interface close to Sensor 4. Localization errors are primarily related to the approximation of the wave velocity.

Fig. 11 shows the results from the moment tensor analysis at three time intervals. No significant events were detected during the first $200 \mathrm{~s}$. This confirms that the activities detected in the parameter analysis were primarily associated with the interaction between the grips and the rebar. Diffused activity above the interface was recorded in the 200-450 s range because of the formation of microcracks. Any transient wave generated in the rebar propagates in the steel waveguide and leaks through the interface into the concrete. Such a wave is converted into a p-wave and into an s-wave, which is then detected by Sensors 1-6. The activities clustered near the plane made by Sensors 4, 5, and 6 may also be associated with the waves' energy leaking from the rebar.

After $450 \mathrm{~s}$, one main cluster is visible around the bond. At this stage of the experiment this activity is associated with macrocracks' formation and the friction between the ribs and the surrounding materials.
Counts, amplitude, and rise time of the AE activity recorded by Sensors 1, 4, and 7 during Test 5 are plotted as functions of time in Figs. 12(a)-12(c). The applied load is superimposed on the count's plot.

The load pattern is typical of a conventional free rebar subjected to a tensile load. The AE activity located at the initial nonlinear load pattern below $200 \mathrm{~s}$ is clearly visible, and it is associated with grips' adjustment and friction between the grips and the rebar. In the elastic range, high $\mathrm{AE}$ counts and amplitudes were detected by both Sensors 4 and 7. High AE rise times characterize the AE waveforms detected by Sensor 7. Similar to Channel 4 in Test 1, Sensor 5 coplanar to Sensor 4 detected the largest amount of cumulative hits (Fig. 12). It may be argued that events generated in the concrete are more impulsive than AE events generated in the steel. As such, the rise time associated with $\mathrm{AE}$ generated in concrete is expected to be lower.

During the yielding phase comprised between 371 and $447 \mathrm{~s}$, most of the activities were recorded by Sensor 7 only.

The increase of the applied stress during the hardening of the rebar produces microcracks in the concrete and furthers rebar's elongation. It must be pointed out that all the $100 \mathrm{~dB}$ AE amplitudes recorded during the test were associated with the slippage of the grips of the loading machine.

Fig. 13 shows the results of moment tensor analysis for Test 5 . One main cluster near the upper part of the interface is visible. Such
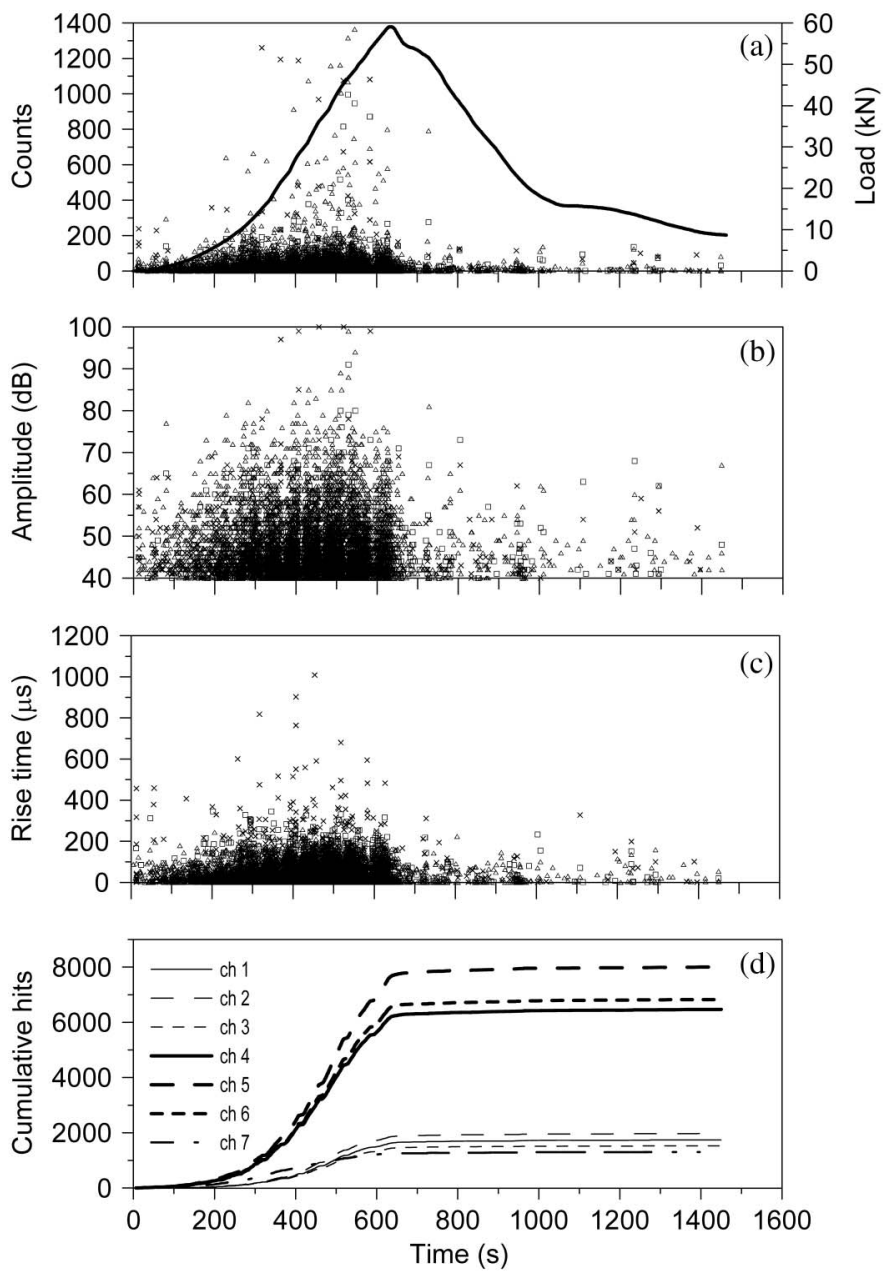

Fig. 14. Test 6 parametric analysis results: (a) counts; (b) amplitude; (c) rise time; (d) cumulative hits; square $(\square)=$ Channel 1; triangle $(\Delta)=$ Channel 4; cross $(x)=$ Channel 7 
an area represented the weakest zone of the bond. The number of shear cracks is less than the number of tensile and mixed cracks. This result agrees with the structural response of the anchor, which reached the proximity of the rebar break.

Counts, amplitude, and rise time of the AE activity recorded by Sensors 1, 4, and 7 during Test 6 are plotted as functions of time in Figs. 14(a)-14(c). The rebar used for Test 1 was used for Test 6. As such, because of the Kaiser effect, no emissions are expected below $84.5 \mathrm{kN}$. All activities recorded during the elastic range are associated with the friction between the rebar and the grips, the interaction between the steel plate and the concrete cylinder, and the debonding at the rebar/resin interface. The effect of
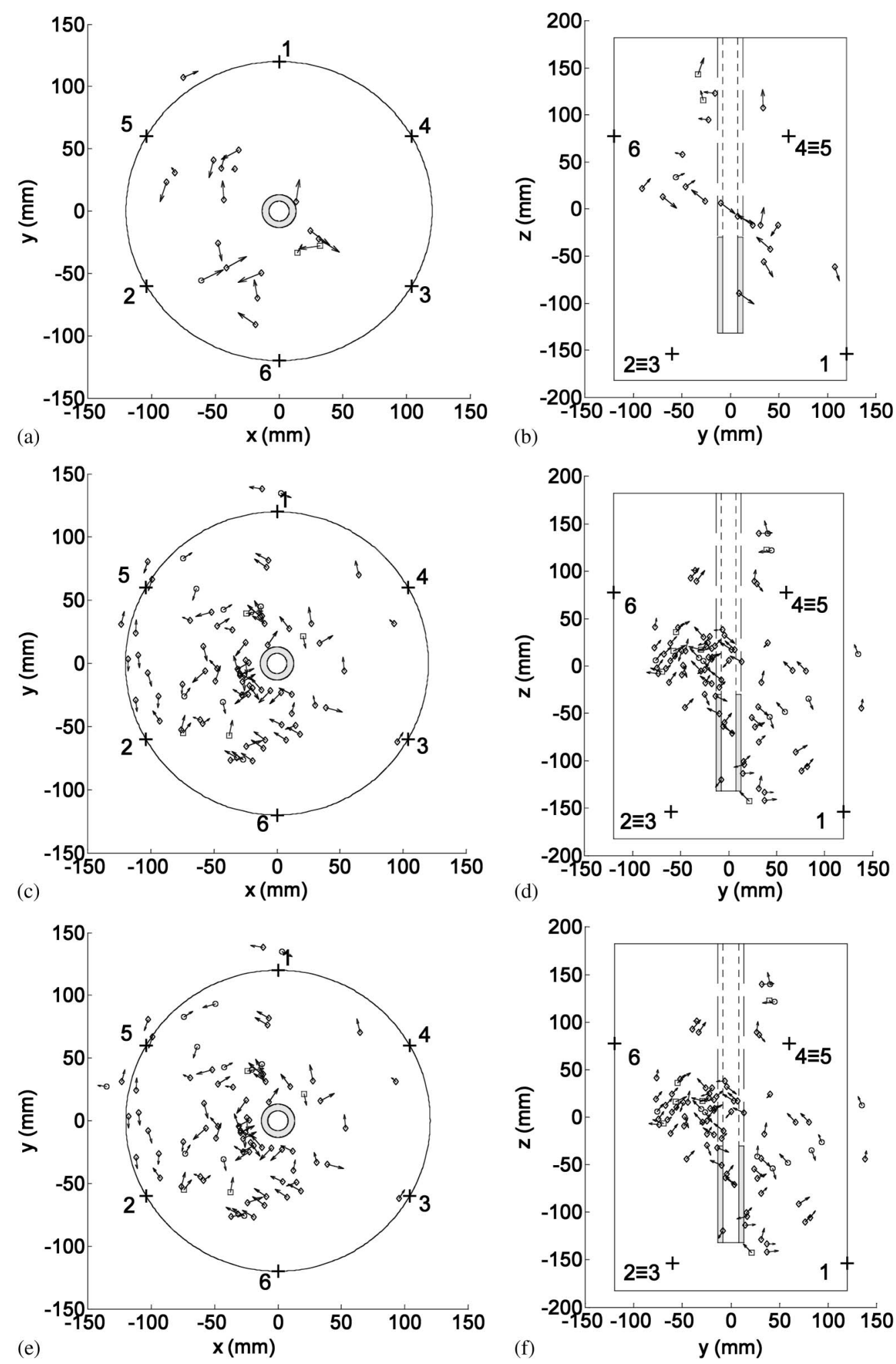

Fig. 15. Test 6 moment tensor results: (a) $0<T<600 \mathrm{~s} x-y$ view; (b) $0<T<600 \mathrm{~s} x-z$ view; (c) $600<T<1,000 \mathrm{~s} x-y$ view; (d) $600<T<1,000 \mathrm{~s} x$-z view; (e) $T>1,000 \mathrm{~s} x$-y view; (f) $T>1,000 \mathrm{~s} x$ - $z$ view; plus $(+)=$ sensor's position; diamond $(\diamond)=$ shear cracks; square $(\square)=$ tensile cracks; circle $(\bigcirc)=$ mixed cracks 
the grips is still visible at the beginning of the test, but it is not as dominant as in the previous tests. An increasing activity is visible as the load approaches the peak [Figs. 14(a)-14(c)]. As visible in Fig. 14(d), which presents the cumulative hits recorded by every channel as a function of time, the largest number of hits was detected by Sensor 5. By comparing the cumulative hits detected by Channel 7 in Fig. 14(d) with Fig. 9(d), the Kaiser effect is evident. After the peak load was reached, the number of emissions was reduced because macrocracks diffused at the interface, and frictional effects were present during the softening branch.

Fig. 15 presents the results of the moment tensor analysis applied to Test 6 . The position, type, and direction of cracks are shown. As expected, cracks are primarily located around the rebar. From the plan view presented in Figs. 15(a) and 15(c), most of the activities are clustered in the region near Sensors 2, 5, and 6. Shear cracks are predominant for Test 1. Comparing the results of the moment tensor analysis occurred at three separate time intervals; it is evident that during the softening branch most of the activity was localized at the interface, and therefore it was associated with frictional activities and further onset and propagation of macrocracks.

\section{Conclusions}

In this paper, the pullout response of epoxy adhesive anchor systems was studied numerically and experimentally to validate the theoretical elastoplastic damaging model introduced in the companion paper (Part I). The anchor consisted of a concrete cylinder with a steel rebar embedded into the hardened concrete by means of polyester resin.

The numerical validation consisted of a new finite subroutine in the open-source code FEAP.

The experimental study consisted of six pullout tests. Three anchors had the same bond length and were used to calibrate the model's parameters. Subsequently, numerical and experimental tests on specimens with different bonded lengths were performed. The agreement between experimental and numerical data showed the applicability of the model to predict the failure of anchor systems.

The nondestructive evaluation method of acoustic emission was used to monitor the onset and propagation of damage within the anchor and to provide further means to validate the theoretical model. Particularly, the parametric analysis and the moment tensor analysis were used. It was observed that the acoustic emission activities correlate well with the onset and propagation of microcracks at the interface predicted by the model.

The agreement between the experimental outcomes and the numerical prediction may pave the road for the extension of the novel elastoplastic damaging model to other adhesive systems.

\section{Acknowledgments}

The experimental study presented in this paper was conducted at the Watkins-Haggart Structural Engineering Laboratory at the University of Pittsburgh. The first author conducted this research while visiting University of Pittsburgh under a study abroad fellowship of the University of Palermo's School of Engineering. The support of the University of Pittsburgh through start-up funds available to the second author is acknowledged. The authors wish to thank Dr. Zvi Meiksin and Dr. Kent A. Harries for many helpful discussions.

\section{References}

Aggelis, D. G., Shiotani, T., and Terazawa, M. (2010). "Assessment of construction joint effect in full-scale concrete beams by acoustic emission activity." J. Eng. Mech., 136(7), 906-912.

ASTM. (1994). "Standard test method for static modulus of elasticity and Poisson's ratio of concrete in compression." C469-94, West Conshohocken, PA, 248-251.

ASTM. (1998). "Standard practise for capping cylindrical concrete specimens." C617-98, West Conshohocken, PA, 305-309.

ASTM. (2001). "Standard test method for compressive strength of cylindrical concrete specimens." C39/C 39M-01, West Conshohocken, PA, 18-22.

Balázs, G. L., Grosse, C. U., Koch, R., and Reinhardt, H. W. (1996). "Damage accumulation on deformed steel bar to concrete interaction detected by acoustic emission technique." Magazine Concr. Res. 48(177), 311-320.

Chang, S. H., and Lee, C. I. (2004). "Estimation of cracking and damage mechanisms in rock under triaxial compression by moment tensor analysis of acoustic emission.” Int. J. Rock Mech. Min. Sci. Geomech. Abstr., 41(7), 1069-1086.

Chen, H. L., and Wissawapaisal, K. (2000). "Study of acoustic surface waveguides on reinforced concrete slabs." J. Nondestruct. Eval., 19(4), 129-140.

Colombo, S., Main, I. G., and Forde, M. C. (2003). "Assessing damage of reinforced concrete beam using ' $b$-value' analysis of acoustic emission signals." J. Mater. Civ. Eng., 15(3), 280-286.

Degala, S., Rizzo, P., Ramanathan, K., and Harries, K. A. (2009). "Acoustic emission monitoring of CFRP reinforced concrete slabs." Constr. Build. Mat., 23(5), 2016-2026.

Fink, F. (2001). "Application of the moment tensor inversion in material testing." Otto-Graf-J., 12(1), 145-156.

Gostautas, R. S., Ramirez, G., Peterman, R. J., and Meggers, D. (2005). "Acoustic emission monitoring and analysis of glass fiber-reinforced composites bridge decks." J. Bridge Eng., 10(6), 713-721.

Grosse, C. U., Reinhardt, H. W., and Fink, F. (2003). "Signal-based acoustic emission techniques in civil engineering." J. Mater. Civ. Eng., 15(3), 274-279.

Guo, D., Mal, A., and Ono, K. (1997). "Lamb waves from microfractures in composite plates." Rev. Prog. Quant. Nondestr. Eval., 16, 397-404.

Huguet, S., Godin, N., Gaertner, R., Salmon, L., and Villard, D. (2002). "Use of acoustic emission to identify damage modes in glass fiber reinforced polyester." Compos. Sci. Technol., 62(10), 1433-1444.

Köppel, S., and Grosse, C. (2000). "Advanced acoustic emission techniques for failure analysis in concrete."〈http://www.ndt.net/article/wcndt00/ papers/idn231/idn231.htm $\rangle$.

Landis, E. N., and Shah, S. P. (1993). "Recovery of microcrack parameters in mortar using quantitative acoustic emission." J. Nondestruct. Eval., 12(4), 219-232.

Lavrov, A. (2001). "Kaiser effect observation in brittle rock cyclically loaded with different loading rates." Int. J. Mech. Mater., 33(11), 669-677.

Matta, F., Rizzo, P., Karbhari, V., and Lanza di Scalea, F., F. (2006). "Acoustic emission damage assessment of steel/CFRP adhesive bonds for rehabilitation." J. Compos. Constr., 10(3), 265-274.

Mizutani, Y., Nagashima, K., Takemoto, M., and Ohno, K. (2000). "Fracture mechanism characterization of cross-ply carbon-fiber composites using acoustic emission analysis." NDT\&E Int., 33(2), 101-110.

National Transportation Safety Board (NTSB). (2007). "Ceiling collapse in the Interstate 90 connector tunnel Boston Massachusetts July 10, 2006." Accident Rep. NTSB/HAR-07/02 PB2007-916203, Washington, DC.

Ohno, K., and Ohtsu, M. (2010). "Crack classification in concrete based on acoustic emission." Constr. Build. Mater., 24(12), 2339-2346.

Ohno, K., Shimozono, S., and Ohtsu, M. (2007). "Cracking mechanisms of diagonal-shear failure monitored and identified by AE-SiGMA analysis." 6th Int. Conf. on Fracture Mechanics of Concrete and Concrete Structures, Taylor \& Francis, London, 991-998.

Ohtsu, M. (1995). "Acoustic emission theory for moment tensor analysis." Res. Nondestr. Eval., 6(1), 169-184. 
Press, W. H., Teukolsky, S. A., Vetterling, W. T., and Flannery, B. P. (1992). Numerical recipes in C, 2nd Ed., Cambridge University Press, Cambridge, UK.

Qi, G. (2000). "Wavelet-based AE characterization of composite materials." NDT\&E Int., 33(3), 133-144.

Ranjith, P. G., Jasinge, D., Song, J. Y., and Choi, S. K. (2008). "A study of the effect of displacement rate and moisture content on the mechanical properties of concrete: use of acoustic emission." Int. J. Mech. Mater., 40(6), 453-469.

Rizzo, P., and Lanza di Scalea, F. (2001). "Acoustic emission monitoring of carbon-fiber-reinforced-polymer bridge stay cables in large-scale testing." Exp. Mech., 41(3), 282-290.

Rizzo, P., Spada, A., Degala, S., and Giambanco, G. (2010). "Acoustic emission monitoring of chemically bonded anchors." J. Nondestruct. Eval., 29(1), 49-61.

Schumacher, T., Higgins, C. C., and Lovejoy, S. C. (2011). "Estimating operating load conditions on reinforced concrete highway bridges with $b$-value analysis from acoustic emission monitoring." Int. J. Struct. Health Monit., 10(1), 17-32.

Shiotani, T., Fujii, K., Aoki, T., and Amou, K. (1994). "Evaluation of progressive failure using $\mathrm{AE}$ sources and improved $b$-value on slope model tests." J. Acoust. Emiss., VII(7), 529-534.

Shull, P. J. (2002). Nondestructive evaluation: Theory, techniques, and applications, Marcel Dekker, New York.

Spada, A., Giambanco, G., and Rizzo, P. (2009). "Damage and plasticity at the interfaces in composite materials and structures." Comp. Meth. Appl. Mech. Engr., 198(49-52), 3884-3901.

Suaris, W., and Van Meier, J. G. M. (1995). "Acoustic emission source characterization in concrete under biaxial loading." Mater. Struct., 28(8), 444-449.

Taylor, R. L. (2005a). "FEAP_A finite element analysis program. Version 7.5 programmer manual." Univ. of California, Berkeley, CA.

Taylor, R. L. (2005b). "FEAP_A finite element analysis program. Version 7.5 user manual." Univ. of California, Berkeley, CA. 